\title{
Application of an amphoteric polymer for leather pickling to obtain a less total dissolved solids residual process
}

\author{
Lu Jia $^{1}$, Jianzhong Ma ${ }^{1,2 *}$, Dangge Gao ${ }^{1 *}$, Bin Lyu ${ }^{1,2}$, Jing Zhang ${ }^{3}$
}

1. College of Resources and Environment, Shaanxi University of Science \& Technology, Xi'an 710021, China;

2. Shaanxi Research Institute of Agricultural Products Processing Technology, Xi'an 710021, Shaanxi, China;

3. College of Arts and Sciences, Shaanxi University of Science \& Technology, Xi'an 710021, China.

${ }^{*}$ Corresponding author. College of Resources \& Environment, Shaanxi University of Science \& Technology, Xi'an 710021, China. Tel.:+86 (0)29 86168006; fax:+86(0)29 86168012.

E-mail: majz@sust.edu.cn (J. Z. Ma)

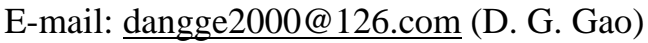


Abstract: A clean approach of less total dissolved solids residual process based on an amphoteric polymer has been attempted. Amphoteric polymer was added in the pickling as experimental process. The amount of common salt reduced from $8 \%$ to $2 \%$ and the amount of basic chrome sulfate was $4 \% .8 \%$ common salt was added in pickling and $4 \%$ basic chrome sulfate was added in tanning as control. The tanning waste water, wet blue and crust leathers were analysed. The results showed that the amphoteric polymer resulted in increment of $\mathrm{Cr}_{2} \mathrm{O}_{3}$ content in leather by $10.8 \%$, and the amphoteric polymer offered leather showed better chromium distribution and collagen fibers distribution properties than conventional leather. The mechanical properties, colour value and shrinkage temperature of the leather treated with amphoteric polymer were close to those of the conventional leather. What's more, the $\mathrm{Cr}_{2} \mathrm{O}_{3}$ content of experimental tanning waste reduced by $53.5 \%$, and the reduction in $\mathrm{Cl}^{-}$content is $78.3 \%$, and the total dissolved solids in the experimental waste reduced to $178.11 \mathrm{~g} / \mathrm{L}$. From the results obtained, it is suggested that without affecting the quality of the finished leather, the amphoteric polymer offered process could reduce the pollution of tanning waste, and promote the development of cleaner production.

Key words: less TDS residual process; amphoteric polymer;low-salt pickling; less chrome tanning; environmental friendly; leather process;

\section{Introduction}

In conventional leather making process, chrome tanning involves pre-treatment of bated hide with sulphuric acid and formic acid to attain an equilibrium $\mathrm{pH}$ of 2.8-3.0. This operation is termed as pickling. The pickled hides are treated with neutral salts $(\mathrm{NaCl}) 6-8 \%$ (on weight of hide or skin) to avoid the swelling of leather collagen. Then $6 \%-8 \%$ basic 
chrome sulfate (BCS) was added in the same bath. Hide can be converted into leather by tanning process (Sundar et al., 2002), so the tanning waste contains large amounts of $\mathrm{Cr}^{3+}$ and neutral salts, which may lead to an increase in total dissolved solids (TDS) in the effluents and is harmful to the environment (Sundar et al., 2013).

The neutral salt used in pickling is almost sodium chloride $(\mathrm{NaCl})$. Chloride ions are easily soluble in water and hard to be eliminated from the waste water. So the tannery effluents have a high osmotic pressure, which may complicate the wastewater treatment steps. However, the conventional chrome tanning process gives only about $60-70 \% \mathrm{w} / \mathrm{w}$ chromium uptake and the remaining is discharged into wastewater. This leads to serious pollution problem. Chromium at higher concentration level affects the soil, fresh water, fish and aquatic organism. (Kanagaraj et al., 2015). Water pollution caused by neutral salts and chromium from leather industry tanning effluents has gained much attention worldwide.

To overcome the environmental problems of TDS caused by neutral salts, several authors have reported to recycle the tanning waste (Morera et al., 2011). This method can reuse neutral salts and chromium, and it looks like very economical. However, with the increase of recycle times, the salinity of the recycle water is high and leather product is very tinny. A lot of waste protein in recycle water may combine with chromium and influence the properties of leather product.

Besides non-swelling acids, naphthalene sulfonic acid and phenol sulfonic acid were used to reduce the pollution of neutral salts (Palop and Marsal, 2002), but the cost of these acids are higher than that of sulphuric acid and formic, and their application in pickling can not bring any other advantages. Nowadays, several authors develop different kinds of pickling 
additives. Most of the pickling additives also play an important role in enhancing the absorption of chrome and produce masking effect to chromium in the tanning process, such as carboxylic acid polymer (Suresh et al., 2001) and oxazolidine (Li et al., 2009), but these additives cause nonuniform distribution of chromium inside leather. Tanning at high $\mathrm{pH}$ is another method to avoid addition of acid and common salt, and this methodology evolved has proven commercial viability with significant cost benefits (Sundar et al., 2013).

There are several methods for minimising chromium pollution. One way is changing the tanning process to obtain a cleaner production, and the two main categories are as following: (i) by using chrome-free tannage (ii) by high exhaust chrome (or less chrome) tanning systems. The chrome-free tannages include metal tannage (Zuriaga-Agustí et al., 2015), phosphonium salt tannage (Shao et al., 2008), aldehydes tannage (Krishnamoorthy et al., 2013; Li et al., 2009), polymer tannage (Luo et al., 2014), unnatural amino acids (Krishnamoorthy et al., 2012) and nano material tannage (Fan et al., 2004). Although chrome-free tanning process can eliminate chromium pollution completely, the above chrome-free tanning materials increase the cost of tanning and also have low resource availability. What's more, their application properties are not as good as chrome.

There are different exhaust chrome (or less chrome) tanning additives, including nanocomposite (Ma et al., 2014), oxazolidine (Sundarapandiyan et al., c), polymer (Kanagaraj et al., 2007). Compared to chrome-free tanning additives, high exhaust chrome (or less chrome) tanning additives not only have simple application process, but also take advantage of chromium to ensure the quality of the finished leather.

In recent years, some researchers try to realize clean leather making by the change of the 
process: such as evaluation a dehydration process for bovine hides (Bacardit et al., 2015), application of supercritical carbon dioxide in leather process (Hu and Deng, 2016), application of ultrasound assisted in chrome tanning (Mengistie et al., 2016), and so on. Introducing different technology in leather process can solve the environmental problems, but equipment for the process is relatively complex and expensive, so they are not suitable for the large-scale leather production.

For most of tanneries, they have relatively stable leather making technology. They would not like to accept the new technology with complex operation. The cleaner technology with simple operation is acceptable to most of the tanneries. Some cleaner technologies used in leather produce may change too much to conventional pickling and tanning process, which are hard to be industrialized. In our research, a clean approach of less TDS residual process (i.e. low-salt pickling and less chrome tanning process) based on an amphoteric polymers (AP) has been attempted. In this process, AP was add to bated hide drumming for 1 hour, and then acid and $\mathrm{NaCl}$ were added to continue pickling. AP plays important roles as pickling auxiliary and pre-tanning agent in the experimental process. The tanning conditions of AP, physic-chemical characteristics, colour value of leathers and the environmental impact of these pickling methods have been compared with conventional tanning process.

\section{Materials and methods}

\subsection{Material}

Dimethyl diallyl ammonium chloride (DMDAAC, 60\%, Shandong Luyue Chemical Industry Co. Ltd., China), acrylic acid (AA, AR, Tianjin Fuchen Chemical Reagents Factory), sodium allyl sulfonate(SAS, AR, Chengdu Huaxia Reagent Co., LTD), ammonium persulfate 
(APS, AR, Tianjin Hengxing Chemical Reagent Manufacturing Co. Ltd., China), sodium hydrogen sulfite $\left(\mathrm{NaHSO}_{3}\right.$, AR, Tianjin Tianli Chemical Reagent Co. Ltd., China), all the reagents were used as received.

Raw material used for leather processing was bated cow hide processed from wet salted cow hide. The chemicals employed in the subsequent operations were those normally used in leather industry. All the other chemicals were commercial grade products. Basic chrome sulfate (BCS) (33\% basicity) Tankrom-AB was supplied by Turkey KROMSAN group and was used as chrome tanning agent.

\subsection{Method}

\subsubsection{Synthesis of amphoteric polymers (AP)}

The synthetic route of AP is presented in Scheme 1. Under continuous stirring, monomer mixture DMDAAC $(60 \%, 56.34 \mathrm{~g})$ and AA $(36 \mathrm{~g})$ were poured into a $250 \mathrm{~mL}$ three-neck-flask equipped with a digital agitator and a reflux condenser in a water bath at $80^{\circ} \mathrm{C}$. Initiator solution (I) was obtained by dissolving $6.79 \mathrm{~g}$ APS in $67.9 \mathrm{~g}$ deionized water; initiator solution (II) was added $1.70 \mathrm{~g} \mathrm{NaHSO}_{3}$ in $17 \mathrm{~g}$ deionized water. SAS solution was obtained by dissolving 15.06g SAS in 8g deionized water. Initiator solution (I), (II) and $102.4 \mathrm{~g}$ deionized water were added in the flask, and SAS solution was added dropwise into the reaction mixture for $0.5 \mathrm{~h}$. After $4 \mathrm{~h}$, the solution was cooled to room temperature and the $\mathrm{pH}$ of the solution was adjusted to about 5.0 by $30 \%$ sodium hydroxide solution. GPC: Mn[348 (PDI: 2.418); 2.8 $\times 10^{4}$ (PDI: 2.090)].

\subsubsection{Optimization of $\mathrm{NaCl}$ input}

In conventional pickling process, $6 \%-8 \%$ basic chromium sulphate $(\mathrm{NaCl})$ is added to avoid the acid swelling of hide. AP can avoid acid swelling of the hide. The bated hide was 
treated with six different amount of $\mathrm{NaCl}$ viz., $1 \%, 2 \%, 3 \%, 4 \%, 5 \%$, and $6 \%$ in order to optimize the effective $\mathrm{NaCl}$ input of $\mathrm{AP}$ pickling process at $\mathrm{pH} 3.0$ (pH was adjusted by formic acid). We also carried out the same procedure of conventional pickling process without AP input.

\subsubsection{Comparison of conventional and AP pickling process}

Bated cow hide was sampled along the spine line to get two symmetrical hides, and one part was for experimental (i.e. less-salt pickling and tanning process with AP input), and another part was for conventional pickling and tanning process. The specific pickling and tanning operations of both conventional and experimental processes are shown in Table 1. The post tanning processes for both experimental and conventional tanned leathers were the same according to the cattle shoe upper leather production process. The operations are shown in Table 2.

\subsection{Shrinkage temperature}

The shrinkage temperature of wet blue was tested by a shrinkage tester (MSW-YD4 Sunshine Electronic Research Institute of Shaanxi University of Science and Technology) to indicate the cross linking extent in tanned leather.

\subsection{Wastewater analysis}

The chromium content in wastewater was analysed using IUC 8 of IULTCS method (IUC 8., 1998), and the wastewater including tanning, retanning waste and chromium wash-out from filling, colour fixing and top dyeing processes. Similarly the chromium content in leather was also estimated following the same procedure (IUC 8., 1998). The waste water was analysed for total dissolved solids (TDS), chlorides using the American wastewater 
Association method (AWWA. 1998). The tanning waste water and post tanning processes integrated waste were collected and analysed for chemical oxygen demand $\left(\mathrm{COD}_{\mathrm{Cr}}\right)$ by using a standard procedure (AWWA. 1998). Biochemical oxygen demand $\left(\mathrm{BOD}_{5}\right)$ was tested by BOD tester (BOD TrakII HACH) and total organic carbon (TOC) was tested by TOC tester (Liqui TOC II Elementar).

\subsection{Strength properties and softness of leather}

All the leather samples were conditioned at standard atmosphere over a period of $48 \mathrm{~h}$ before test. For strength properties test, the dried leather samples were cut into rectangular strips, and the tensile strength, elongation at break were tested according to IUP 6 (IUP 6 ., 2000) and the tear strength was tested followed IUP 8 (IUP 8., 2000). The softness of leather sample was tested by softness tester following the standard procedures GT 303 (Gotech Testing Machines Co., Ltd)

\subsection{Colour value of crust leathers}

The colour values of the dyed crust leathers were made by reflectance measurements. Colour values such as L, a, b, were measured using X-rite SP64. L is the measure of lightness difference; ' $a$ ' represents red and green axis and 'b' represents yellow and blue axis.

\subsection{EDS analysis}

The distribution of chromium of conventional and experimental crust leathers was tested by energy dispersive X-ray spectroscopy (EDS, S4800, Hitachi). Prior to EDS test, the samples were sprayed with gold.

\subsection{ESEM analysis}

The morphology of conventional and experimental crust leathers was tested by 
environment scanning electron microscope (ESEM, FEI Q45, FEI).

\section{Results and discussion}

\subsection{Effect of $\mathrm{NaCl}$ input in $\mathrm{AP}$ pickling process}

In order to investigate the effect of $\mathrm{NaCl}$ input of $\mathrm{AP}$ pickling process, the increased weight for leathers of different $\mathrm{NaCl}$ input at $\mathrm{pH} 3.0$ was considered, and the same procedure without AP input was also conducted. The positively increased weight means the leather is swelling and water penetrates into the leather matrix, which may result in bad mechanical strength to leather. On the other hand, the negative increased weight of leather indicates the $\mathrm{NaCl}$ and $\mathrm{AP}$ can prevent the leather from swelling at $\mathrm{pH}$ 3.0. The increased weight of leathers with different $\mathrm{NaCl}$ input at $\mathrm{pH} 3.0$ is shown in Figure 2. It has been observed from Figure 1 that at least $5 \% \mathrm{NaCl}$ should be added in the traditional pickling process to avoid the swelling of leather, but $1-2 \% \mathrm{NaCl}$ with $\mathrm{AP}$ can avoid the acid swelling of leather efficiently. Furthermore, without $\mathrm{NaCl}$ input, AP process expresses lower increased weight than no AP input process.

As we known, there are three theories for collagen swelling explanation, which are Donnan equilibrium, charge and lyotropic swelling. (Shan and Zhang, 1999) Collagen can be seen as a membrane system in Donnan equilibrium theory, and the Donnan equilibrium can be destroyed when the swelling acid or base is added into the collagen, which may result in collagen swelling due to the increase of the osmotic pressure of collagen. But this theory is unsuitable when $\mathrm{pH}$ of system deviates far from the isoelectric point of collagen. For lyotropic swelling theory, force between collagen molecules can be destroyed by the lyotropic agent, which may result in the swelling of collagen. This theory is suitable for the near-neutral 
$\mathrm{pH}$ condition. According to charge theory, the hide is amphoteric due to carboxylic groups and amino groups on the collagen fibre. When the collagen is under acidic or alkaline conditions, the peptide chain with same charge may result in mutually exclusive of peptide, and this cause the formation of diffusion electric double layer on collagen fiber surface as water exists. So charge theory is suitable when $\mathrm{pH}$ of system deviates far from the isoelectric point of collagen. Our research mainly focus on the roles of AP in pickling process, and the $\mathrm{pH}$ of pickling is about 2.5-3.0. Therefore the roles of AP are mainly discussed by charge theory.

The mechanism of the AP in picking process is shown in Figure 2. The isoelectric point of collagen is about $\mathrm{pH} 5.0$, and the hide is positively charged due to the maximization of the positively charged amino groups on the collagen in traditional pickling bath ( $\mathrm{pH}$ 2.5-3.0). The swelling and disruption of crosslinking can probably be avoided with the presence of $6-8 \%$ neutral salt $(\mathrm{NaCl})$, as Figure 2 (a) shows. ${ }^{13}$ No $\mathrm{NaCl}$ or less $\mathrm{NaCl}$ input in pickling process may lead to the swelling of hide, as Figure 2(b) shows. AP can avoid acid swelling to some extent, because the isoelectric point of $\mathrm{AP}$ is $\mathrm{pH} 4.3$ while the isoelectric point of collagen is close to $\mathrm{pH}$ 5.0. Electrovalent bonds between carboxylic groups, sulfonic groups of AP and the amino groups of collagen are formed when the $\mathrm{pH}$ of the bath is 4.3-5.0 as Figure2(c) shows. We can learn from the vegetable tanning theory that the electrovalent bonds formed by anionic groups and amino group of the collagen are not easily destroyed unless washed by alkali solution (Zhang and Chen, 1999). So the electrovalent bonds are stable as the pickling $\mathrm{pH}$ is 3.0, and the swelling of pickling hide is therefore prevented as amino groups of collagen are uncharged at lower $\mathrm{pH}$. Sulfonic group is a kind of strong acid group and easy ionized 
even if at lower pH condition (Zhang and Chen, 1999), so electrovalent bonds are still formed between sulfonic group of AP and amino groups of collagen at $\mathrm{pH} 3.0$. The reaction of AP with amino groups of the collagen side-chains prevents them from combining with hydrogen ions at lower $\mathrm{pH}$ condition. However AP cannot combine with collagen completely, because the distance between collagen fibers is different, and the long polymer chain cannot penetrate into the small fibers gap. So the hide is also swelling if only AP is added, and small amount of neutral salt are still needed. Adjust solution $\mathrm{pH}$ to 3.0 and add $2 \%$ neutral salt, and the osmotic pressure of the solution cannot avoid hide swelling as Figure2(c) shows. Also, the residual AP in the solution increases the osmotic pressure of the solution, which also avoid the hide swelling. No sulfuric acid added in the process is another reason to reduce the $\mathrm{NaCl}$ amount in pickling process. So the AP pickling can achieve a less salt process, and reduce the $\mathrm{NaCl}$ input to $1-2 \%$.

\section{2 $\mathrm{Cr}_{2} \mathrm{O}_{3}$ content and thermal stability of leathers}

Generally, chromium content may reflect the absorption rate of chromium. The more chromium in leather, the higher the crosslinking degree of chrome and collagen, which may improve leather performance. The chromium content as $\% \mathrm{Cr}_{2} \mathrm{O}_{3}$ (based on dry weight) in wet blue and resultant leather in the case of experimental and conventional process is given in Table 3. The results indicate that chromium content was more in the experimental wet blue and resultant leather compared to the conventional leathers. Shrinkage temperature of bated hides and wet blue in the case of experimental and conventional process is shown in Table 3. The shrinkage temperature of experimental bated hide was smaller before leather tanning, but the shrinkage temperature of wet blue was close to the conventional leather. 
The addition of AP to the hide was better for the chromium uptake, and this result was consistent with the chromium content in the waste which has been discussed in previous section. In general, the higher $\mathrm{Cr}_{2} \mathrm{O}_{3}$ content in leather may prompt better hydrothermal stability of wet blue, but shrinkage temperature in Table 3 was not significantly improved for experimental process compared with conventional process. This may be because there was more single-site binding and not enough multi-site binding in experimental leather, and single-site binding has little effect on shrinkage temperature. Compared with conventional process, the chromium wash-out of experimental post tanning process was less, which indicated the better crosslinking in leather by the active group on AP, chromium and collagen fibers.

\subsection{Physical characteristics and softness of leathers}

The physical characteristics of leathers reflect the quality of leather. The physical testing characteristics of the resultant leathers are shown in Figure 3. The results indicate that strength properties such as tensile strength, tear strength, elongation at break of experimental leather are better than those of conventional one. Because more chromium in leather can improve the overall performance of the leather.

The softness of leather is one of the main sensory index for the leather quality. The softness of the resultant leathers is shown in Figure 4. The softness of experimental leather is better because the polymer chains of AP have a lubricating effect on the collagen fibers, and the softness of leather is improved (Wang et al. 2007).

\subsection{Wastewater analysis}

The comparison of tanning wastewater between conventional and experimental process 
is shown in Table 4. Chromium and $\mathrm{Cl}^{-}$are the main causes of TDS in tanning waste, which may result in serious pollution to the environment mentioned previously. In this research, $\mathrm{Cr}_{2} \mathrm{O}_{3}$ content of experimental tanning waste can be reduced by $53.5 \%$ indicates that $\mathrm{AP}$ exhibited high exhaustion of chromium when compared to normal BCS tanning waste water. AP penetrated into the collagen fibers and introduced active groups to the hide, which promoted the crosslinking between chromium and collagen (Ma et al., 2014). $\mathrm{Cl}^{-}$content of experimental process reduced by $78.3 \%$ compared to the $\mathrm{Cl}^{-}$content of conventional process because less neutral salt was added to the pickling bath. For these reasons, the use of AP could reduce TDS in the waste to get a relatively clean leather making process.

The biochemical oxygen demand $\left(\mathrm{BOD}_{5}\right)$ and the chemical oxygen demand $\left(\mathrm{COD}_{\mathrm{Cr}}\right)$ are commonly used as parameters for determining the degradation of organic compounds (Pi and Gong, 2008). TOC represents the total amount of organic substances, and it can be used to evaluate the degree of organic pollution in water. The $\mathrm{COD}_{\mathrm{Cr}}, \mathrm{BOD}_{5}$, TOC of experimental tanning waste were decreased, indicating AP could lower the content of reducing substances in the waste. This may be because AP played an important role in form crosslinking between chromium and collagen, and the crosslinking effect not only increased the absorption of chromium, but also reduced decomposition of leather. For another reason, sulfuric acid may cause stronger hydrolysis effect to collagen than formic acid. In experimental pickling process, only formic acid added may reduce hydrolysis degree of collagen. What' more, the pelt was smooth after AP was added in the drum, and then the leather became astringent after be drummed for $1 \mathrm{~h}$, indicating the better penetration properties of $\mathrm{AP}$. $\mathrm{BOD}_{5} / \mathrm{COD}_{\mathrm{Cr}}$ evaluates the biodegradability of wastewater. $\mathrm{BOD}_{5} / \mathrm{COD}_{\mathrm{Cr}}$ of experimental waste water is higher, 
which indicates the better biodegradability than conventional waste water, and the results demonstrate that AP pickling process is a cleaner process.

In the post tanning process, a certain amount of $\mathrm{BCS}$ is added in retanning process to ensure the quality of the resultant leather, so the retanning waste contains large amount of chromium, and in the subsequent processes, such as neutralization, dyeing, fat-liquoring, the chromium can be washed out from the leather (Zhou et al., 2012). The chromium in retanning waste and washed-out from subsequent processes of conventional and experimental was shown in Figure 5. In the experimental subsequent process, the chromium washed out was less than the conventional process, indicating the better crosslinking in leather by the active group on AP, chromium and collagen.

The retanning waste water and subsequent processes waste water were collected to form post tanning processes integrated waste for both experimental conventional process, and the $\mathrm{COD}_{\mathrm{Cr}}, \mathrm{BOD}_{5}$, TOC of integrated waste were analysed (shown in Table 5). All the values of experimental process were close to conventional processes, indicating that the AP did not affect the biodegradability of post tanning processes. Despite the fact that AP added before pickling played as a high exhaustion auxiliary and absorbed more chromium into the crust leather in experimental retanning process, so the chromium content reduced.

\subsection{Colour value of crust leathers}

Colour indicators $\mathrm{L}, \mathrm{a}$ and $\mathrm{b}$ difference values of the dyed leathers for experimental and conventional processes are given in the Table 6 . The leathers were coloured by black dye, so the colour of leathers are mainly valued by L. The results show that conventional and experimental leathers have close colour value, indicating that quaternary ammonium groups 
on the amphoteric polymer can avoid the "colour-losing" effect of polyacrylic.

\subsection{Dispersive X-ray spectroscopy (EDS) analysis}

The chromium distribution of leather was analysed by EDS line scanning method. Chromium content of different layers of the crust leather was obtained by scanning from flesh side to grain side of leather longitudinal section shown in Figure 6. As the figure shows, chromium content in conventional leather presents an increasing trend from flesh side to grain side, indicating the chromium penetrates non-uniform from flesh side and grain side. However, the chromium in experimental leather distributed evenly from the flesh side to the grain side. This was owing to the fact that AP could penetrate into leather from both grain side and flesh side to pre-modify collagen and played a stereotypical roles, which was better for chromium penetration and distribution in leather.

\subsection{Environment Scanning Electron Microscope (ESEM) analysis}

The environment scanning electron micrographs (ESEM) of longitudinal section of experimental as well as conventional chrome tanned leathers with magnifications of $\times 1,000$ and $\times 2,000$ are shown in Figure 7. The results indicate that experimental leather (Figure $7 \mathrm{~b}$ and Figure 7d) distributes more uniformly and even loosely than conventional leather (Figure 7a and Figure 7c), which proved AP could contribute to cross-linking between the chromium and collagen and open the gap between the fibers, so the experimental leather showed better performance.

\section{Conclusions}

The cleaner approach to less TDS residual process (i.e. low-salt pickling and less chrome tanning process) based on amphoteric polymers (AP) has been developed. The physical 
characteristics and shrinkage temperature of experimental leathers were close to the conventional chrome tanned leather. AP also can avoid the "colour-losing" effect of polyacrylic. The $\mathrm{Cr}_{2} \mathrm{O}_{3}$ content in $\mathrm{AP}$ offered leather was more than conventional one. Chromium distributed more evenly from the leather flesh side to the grain side, and the collagen fibers were even looser. The important advantages of the AP pickling and tanning process were the better environmental benefits achieved. The AP tanning waste showed reduction in chromium content, $\mathrm{Cl}^{-}$content, TDS, $\mathrm{COD}, \mathrm{BOD}, \mathrm{TOC}$ as compared to conventional process, and the finished leather was up to standard. The study indicates that without affecting the quality of the finished leather, AP offered process could reduce the pollution of tanning waste and promote the development of cleaner production in large-scale.

\section{Acknowledgements}

This work was supported by Natural science foundation research project of Shaanxi Province (2015JM2061); National Science Foundation of China (21406135) and Key Scientific Research Group of Shaanxi province (2013KCT-08).

\section{References}

AWWA., American Water Works Association, 1998. Standard Methods for the Examination of Water and Wastewater.

Bacardit, A., Baquero, G., Sorolla, S., \& Ollé, L., 2015. Evaluation of a new sustainable continuous system for processing bovine leather. J. Clean. Prod., 101, 197-204.

Fan, H.J., He, Q., Peng, B.Y., Liu, H.D., Shi, B., 2004. Study on tanning methods and tanning characteristic of nano-SiO 2 . China Leather, 21, 37-39.

Hu J., Deng W., 2016. Application of supercritical carbon dioxide for leather processing, J. 
Clean. Prod., 113, 931-946.

IUC 8., 1998. Determination of chromium oxide content, J. Soc. Leather Tech. Chem., 82, 200-208.

IUP 6., 2000. Measurement of tensile strength and percentage elongation, J. Soc. Leather Tech. Chem., 84, 317-321.

IUP 8., 2000. Measurement of tear load, J. Soc. Leather Tech. Chem., 84, 327-329.

Kanagaraj, J., Senthilvelan, T., Pand, R.C., Kavitha, S., 2015. Eco-friendly waste management strategies for greener environment towards sustainable development in leather industry: a comprehensive review. J. Clean. Prod., 89, 1-17.

Krishnamoorthy, G., Sadulla, S., Sehgal, P.K., Mandal, A.B., 2013. Greener approach to leather tanning process: d-Lysine aldehyde as novel tanning agent for chrome-free tanning. J. Clean. Prod., 42, 277-286.

Krishnamoorthy, G., Sadulla, S., Sehgal, P.K., 2012. Green chemistry approaches to leather tanning process for making chrome-free leather by unnatural amino acids. J. Hazard. Mater., 190, 215-216.

Kanagaraj, J., Shanmugaiah, V., Sekar, S., Sastry, T.P., 2007. Fibrin hydrolysate as a chrome exhaust aid and retaning agent in the leather production: an approach towards environmental e friendly leather processing. Leather Age, 29, 64-71.

Li, K., Chen, H., Wang, Y., Shan, Z., Yang, J., Brutto, P., 2009. A salt-free pickling regime for hides and skins using oxazolidine. J. Clean. Prod., 17, 1603-1606.

Luo, J.X., Li, J., Wang, S.J., Fei, Y.Y., Li, B., 2014. Application of novel chrome-free tanning agent TWS on cattle hide. China Leather, 3,1-5. 
Mengistie, E., Smets, I., Van Gerven, T., 2016. Ultrasound assisted chrome tanning: Towards a clean leather production technology. Ultrasonics Sonochemistry, 32, 204-212.

Morera, J.M., Bartoli, E., Chico, R., Sole, C., Cabeza, L.F., 2011. Minimization of the environmental impact of chrome tanning: a new process reusing the tanning floats. J. Cleaner Prod., 19, 2128-2132.

Ma, J.Z., Lv, X.J., Gao, D.G., Li, Y., Lv, B., Zhang, J., 2014. Nanocomposite-based green tanning process of suede leather to enhance chromium uptake. J. Cleaner Prod., 72, 120-126.

Pi, K.W., Gong, W.Q., 2008. Biodegradability enhancement of municipal landfill leachate. Water Sci. Eng., 1, 89-98.

Palop, R., Marsal, A., 2002. Auxiliary agents with non-swelling capacity used in pickling/tanning processes. J. Soc. Leather Tech. Ch., 86, 139-42.

Sundar, V.J., Rao, R. J., Muralidharan, C., 2002. Cleaner chrome tanning - emerging options. J. Clean. Prod., 10, 69-74.

Sundar, V. J., Muralidharan, C., Mandal, A.B., 2013. A novel chrome tanning process for minimization of total dissolved solids and chromium in effluents. J. Clean. Prod., 59, 239-244.

Suresh, V., Kanthimathi, M., Thanikaivelan, P., Rao, J.R., Nair, B.U., 2001. An improved producte process for cleaner chrome tanning in leather processing. J. Cleaner Prod., 9, 483-491.

Shao, S.X., Shi, K.Q., Li, Y., Jiang, L., Ma, C.A., 2008. Mechanism of Chrome-free Tanning with Tetra-hydroxymethyl Phosphonium Chloride. Chinese Journal of Chemical 
Engineering, 16, 446-450.

Sundarapandiyan, S., Brutto, P. E., Siddhartha, G., 2011. Enhancement of chromium uptake in tanning using oxazolidine. J. Hazard. Mater., 190, 802-809.

Shan, Z., Zhang, W., 1999. Acid swelling of collagen and inhibition. China Leather, 3, 18-19.

Wang, X. Ch, Zhao, Y.T., Li, T., 2007. Preparation of microemulsion polymer and its influence on softness and physical-mechanical properties of chrome tanned leather. Fine Chem. 25 (8), 784-789.

Zuriaga-Agustí, E., Galiana-Aleixandre, M.V., Bes-Pia, A., Mendoza-Roca, J.A., Risueno-Puchades, V., Segarra, V., 2015. Pollution reduction in an eco-friendly chromefree tanning and evaluation of the biodegradation by composting of the tanned leather wastes. J. Clean. Prod., 87, 874-881.

Zhou, J., Hu, S. X., Wang, Y.N., 2012. Release of chrome tanning and post processes. J. Soc. Leather Tech. Ch., 96, 157-162.

Zhang, M.R., Chen, W.Y., 1999. Tanning chemistry, Vegetable tanning. China Light Industry Press, Beijing, China, pp. 131-133, 169. 
Figure captions:

Scheme 1 The synthetic route of P(DMDAAC-AA-SAS)

Figure 1 The leathers increase weight with different $\mathrm{NaCl}$ input at $\mathrm{pH} 3.0$

Figure2 Mechanism of action of AP as pickle agent

Figure3 Physical testing characteristics of dyed crust leathers

Figure4 The softness of dyed crust leathers

Figure $5 \mathrm{Cr}_{2} \mathrm{O}_{3}$ content in four post tanning processes

Figure6 EDS results of chromium by line scanning of cross section

Figure7 SEM images of conventional (a and c) and experimental (b and d) leather

longitudinal section. $\mathrm{a}, \mathrm{b}$ indicate magnifications of $\times 1,000$ and $\mathrm{c}, \mathrm{d}$ indicate magnifications of $\times 2,000$. 
Figure 1

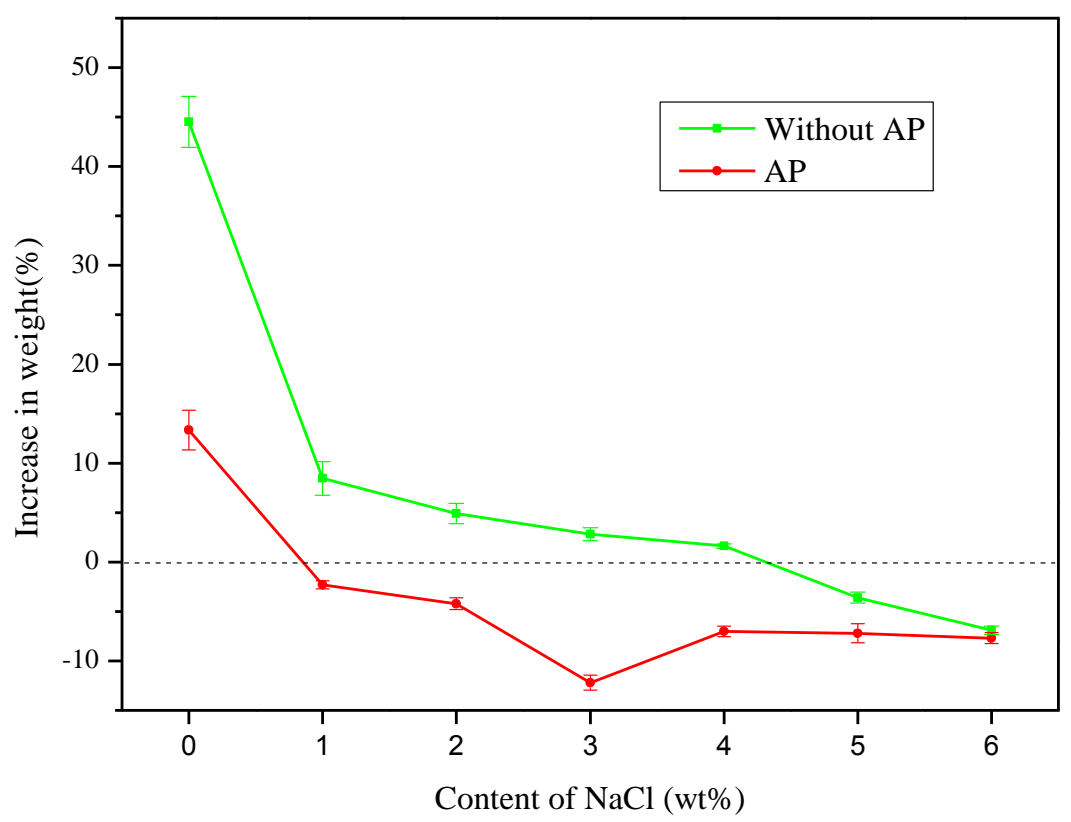


Figure2

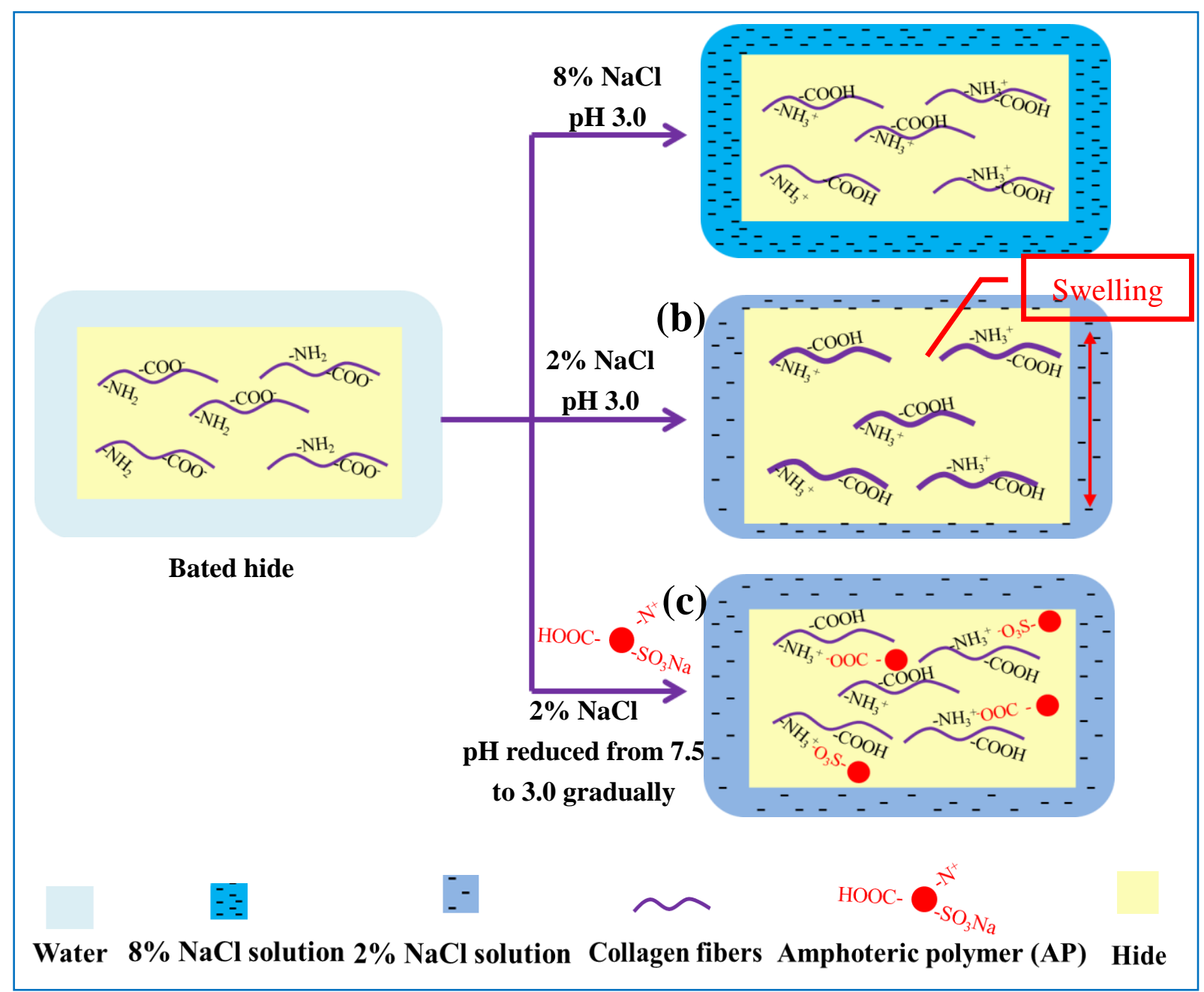


Figure 3

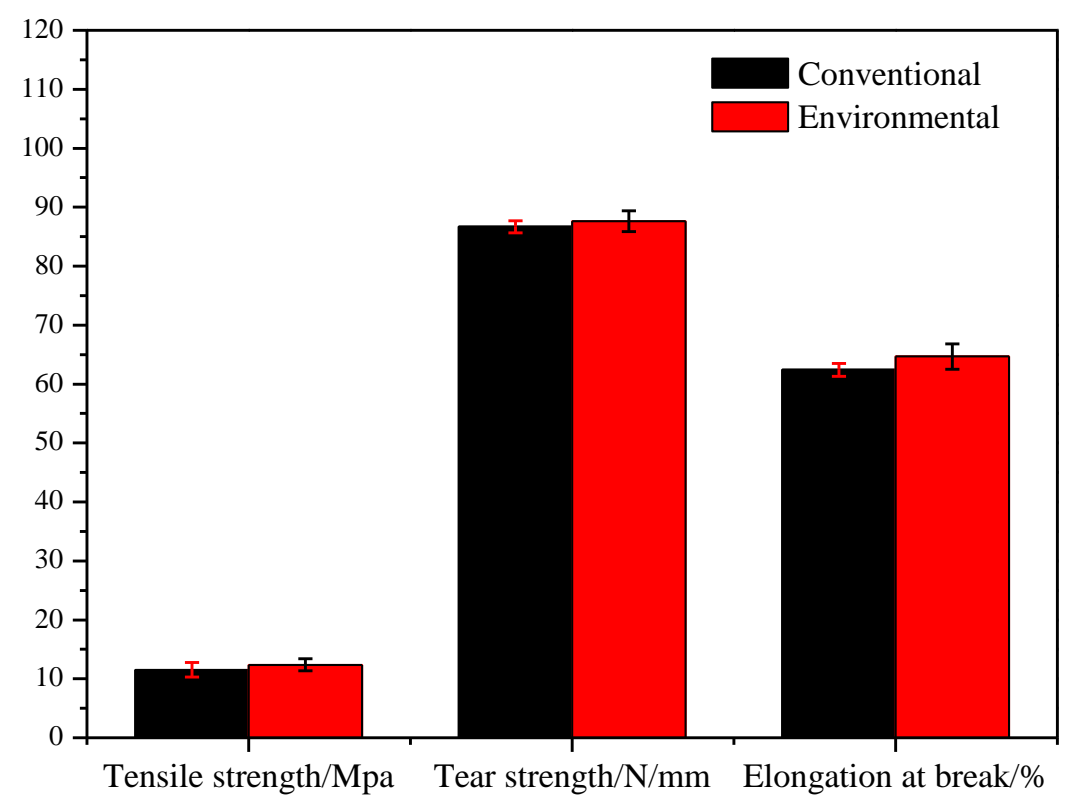


Figure 4

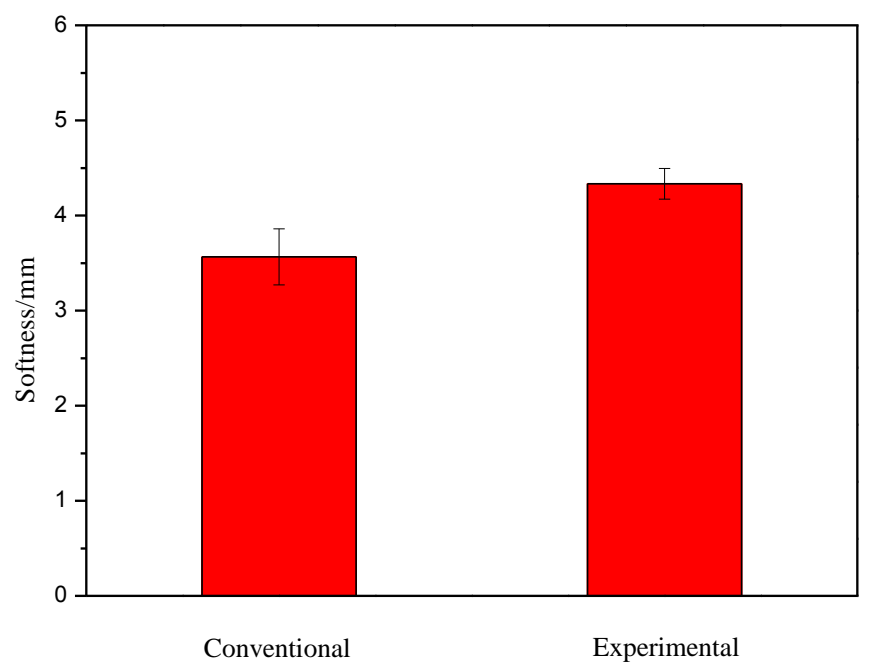


Figure 5

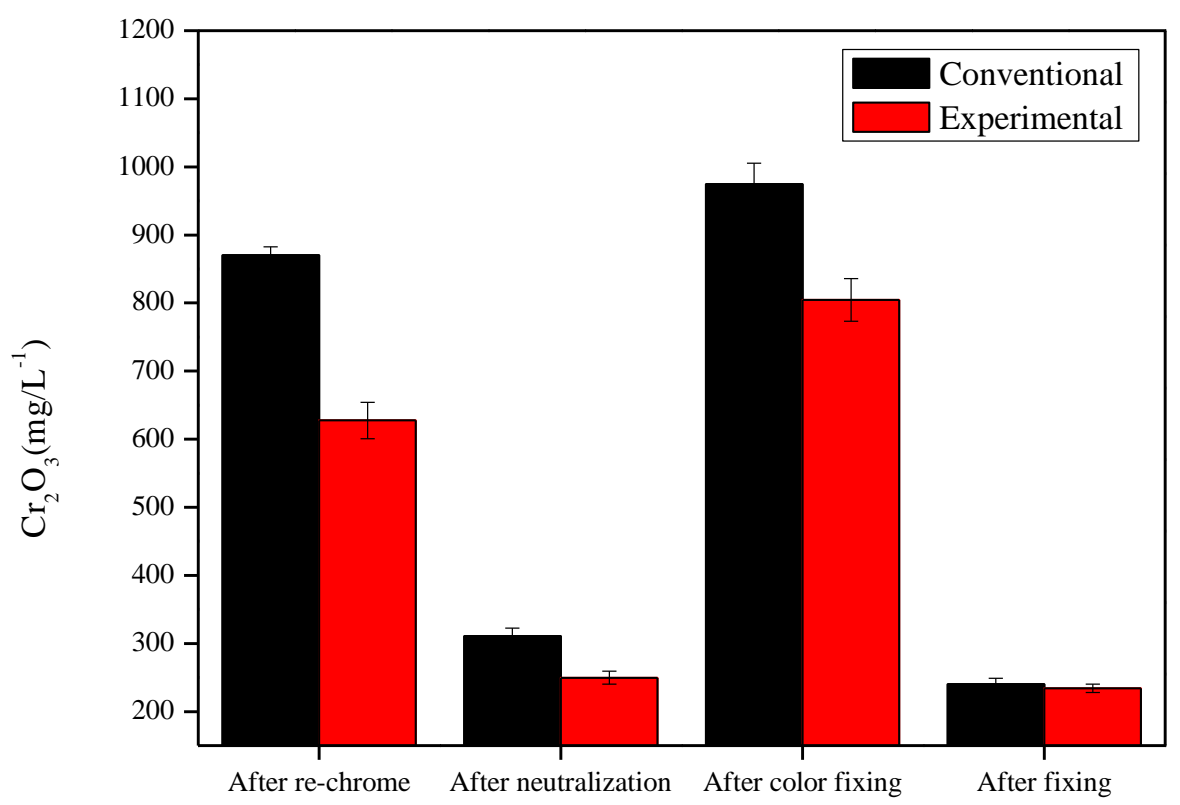


Figure 6

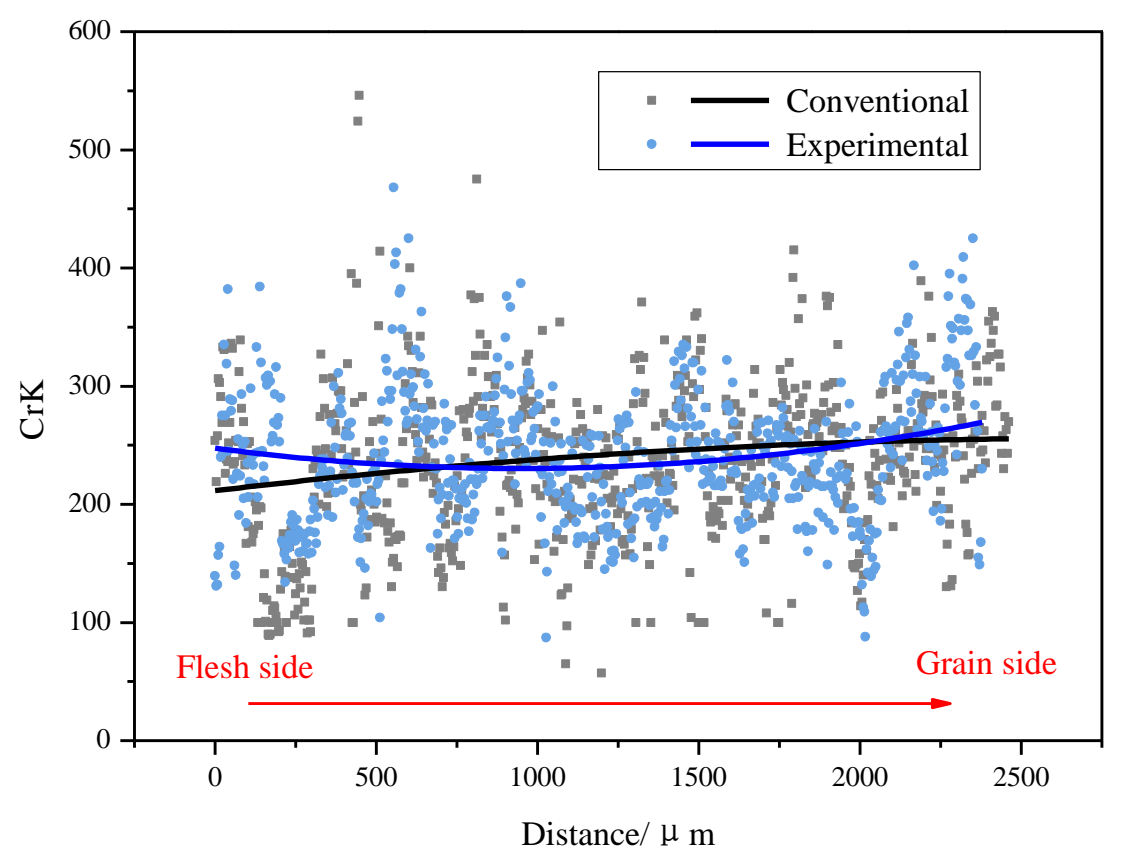




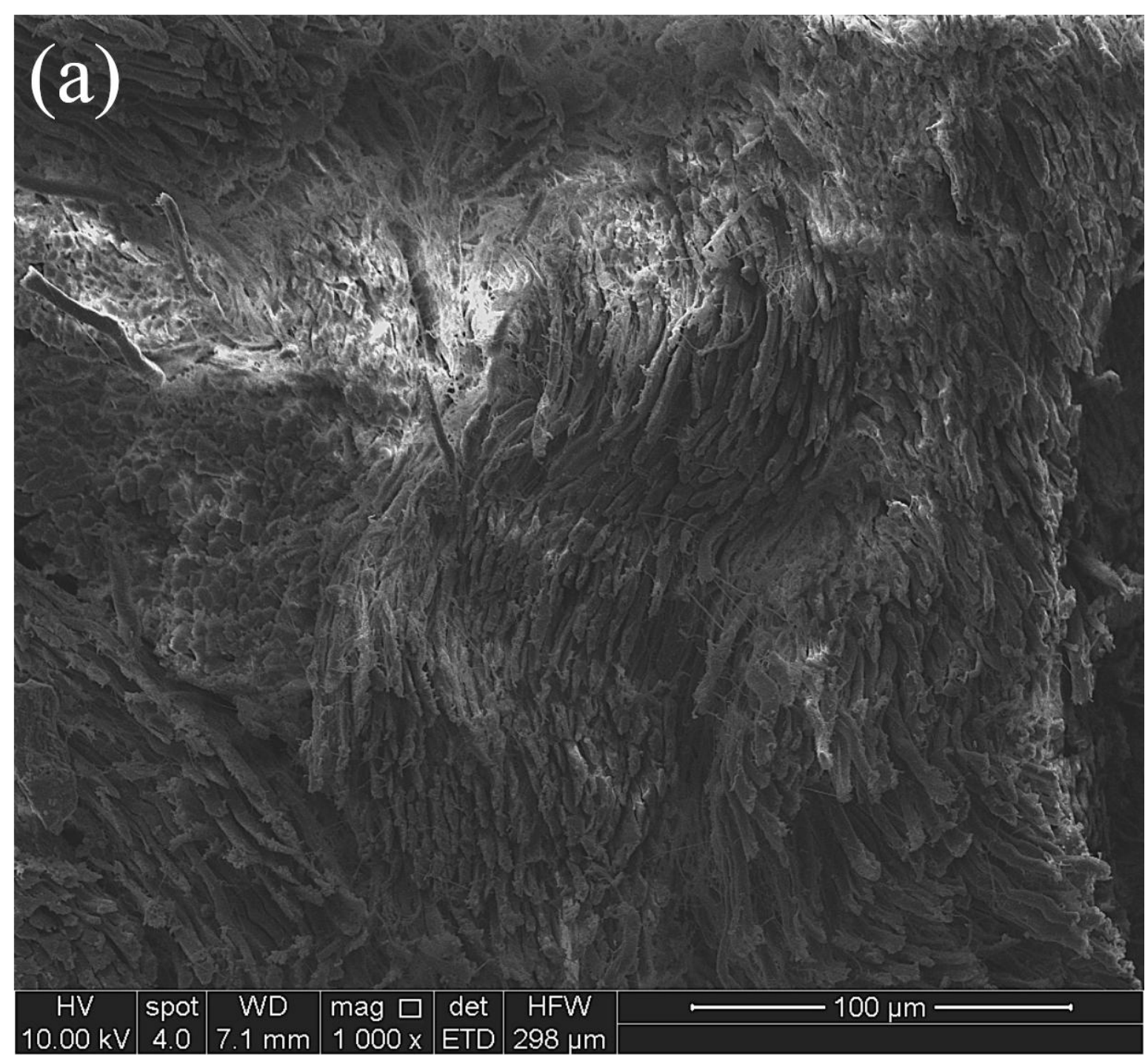




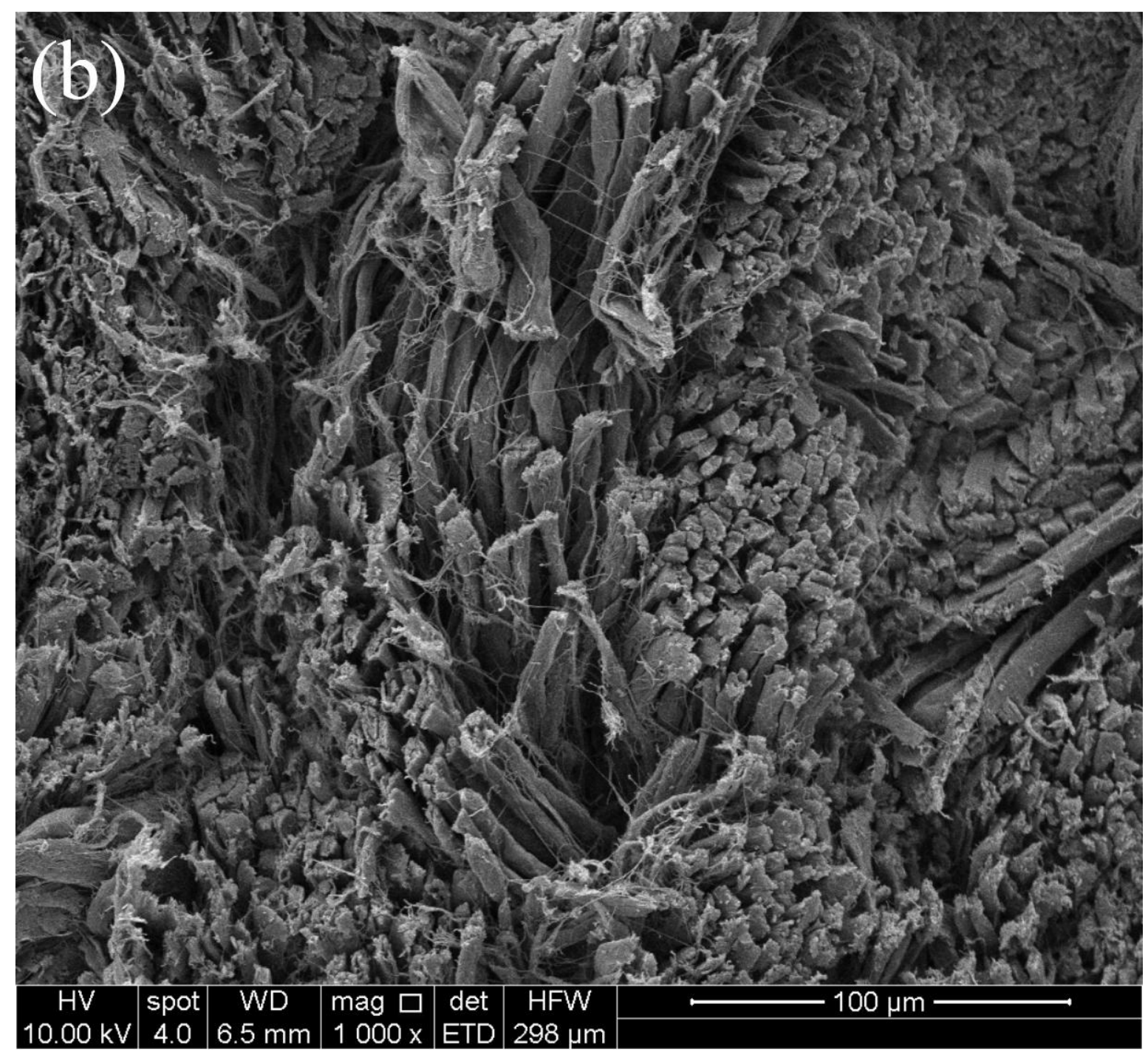




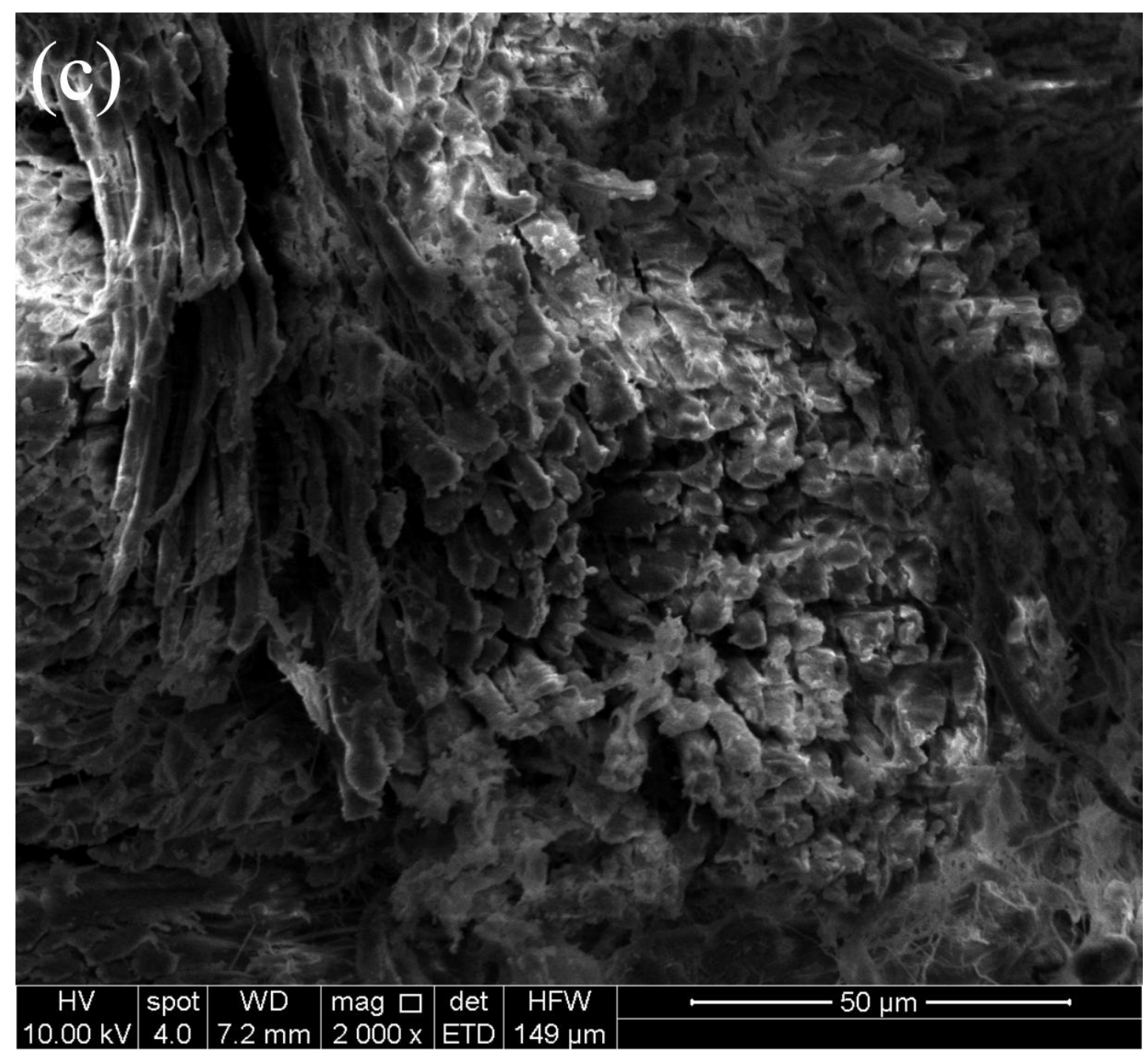




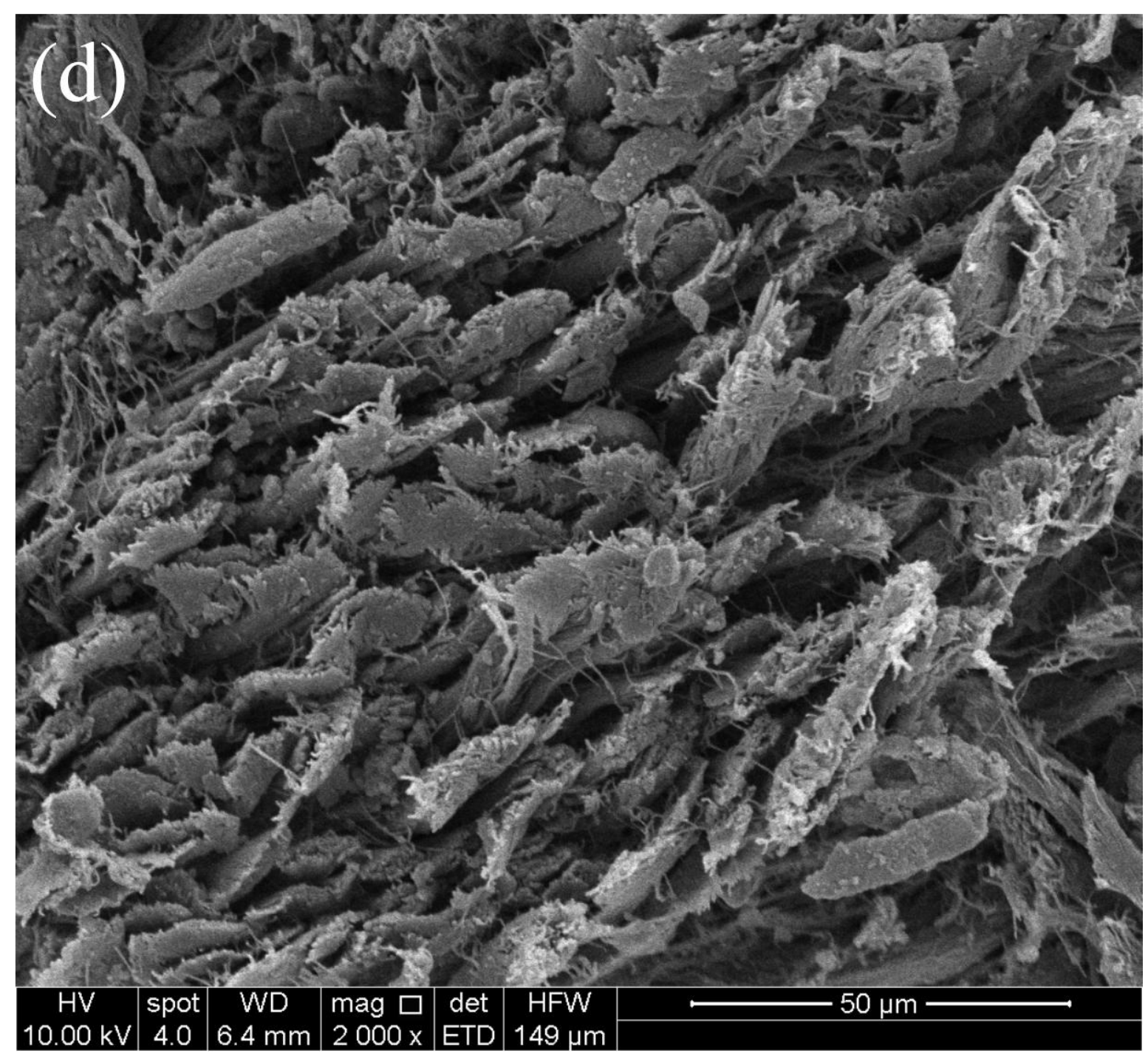


Table captions:

Table 1 The specific pickling and tanning operation of both conventional and experimental processes

Table 2 The specific retanning and fatliquoring for both conventional and experimental processes

Table 3 Properties of wet blue and resultant leather

Table 4 Tanning wastewater analysis

Table 5 Post tanning processes integrated waste

Table 6 Colour value of crust leathers 
Table 1

\begin{tabular}{|c|c|c|c|c|c|c|c|}
\hline & & \multicolumn{3}{|c|}{ Conventional process } & \multicolumn{3}{|c|}{$\begin{array}{l}\text { Experimental process } \\
\text { (AP pickling) }\end{array}$} \\
\hline & & Input/\% & Time/min & $\mathrm{pH}$ & Input $/ \%$ & Time/min & $\mathrm{pH}$ \\
\hline \multirow[t]{6}{*}{ Pickling } & Water & 100 & & & 100 & & \\
\hline & $\mathrm{NaCl}$ & 8 & & & Optimum & & \\
\hline & & & & & value & & \\
\hline & $\mathrm{AP}$ & & & & 3 & 60 & \\
\hline & Sulphuric acid & 0.5 & $2 * 30$ & & & & \\
\hline & Formic acid & 0.8 & $3 * 30$ & 2.8 & 1 & $3 * 30+30$ & 3.0 \\
\hline \multirow[t]{3}{*}{ Tanning } & BCS & 4 & 150 & & 4 & 150 & \\
\hline & Sodium formate & 0.5 & 60 & & 0.5 & 60 & \\
\hline & Sodium bicarbonate & 1.2 & $3 * 30+60$ & 4.1 & 1.2 & $3 * 30+60$ & 4.1 \\
\hline
\end{tabular}


Table 2

\begin{tabular}{|c|c|c|c|c|c|}
\hline Process & Input & Amount $/ \%$ & Temperature $/{ }^{\circ} \mathrm{C}$ & Time/min & Remark \\
\hline \multirow[t]{6}{*}{ Re-chrome } & Water & 100 & 35 & & \\
\hline & Fatty Aldehyde & 2 & & 30 & \\
\hline & $\mathrm{BCS}$ & 4 & & 60 & \\
\hline & Sodium formate & 1.0 & & 30 & \\
\hline & Sodium bicarbonate & 0.5 & & 60 & $\mathrm{pH}: 4.1$ \\
\hline & \multicolumn{5}{|c|}{ Stop, O/N, drain } \\
\hline \multirow[t]{5}{*}{ Neutralization } & Water & 150 & 30 & & \\
\hline & Sodium formate & 1 & & & \\
\hline & Tannin & 2 & & & \\
\hline & Sodium bicarbonate & 0.3 & & 90 & pH: 5.0 \\
\hline & & Wash, drain & & & \\
\hline \multirow[t]{7}{*}{ Retanning } & Water & & 30 & & \\
\hline & Acrylic resin & 5 & & 90 & \\
\hline & Amino Resin & 7 & & & \\
\hline & Syntan & 4 & & & \\
\hline & Tannin extract & 4 & & & \\
\hline & Dispersion tannin & 1 & & & \\
\hline & Dye & 3 & & 90 & \\
\hline \multirow[t]{3}{*}{ Color Fixing } & Formic acid & 0.5 & 30 & 20 & \\
\hline & Formic acid & 1.0 & & 30 & \\
\hline & $\mathrm{BCS}$ & 2.50 & & 60 & pH: 4.0 \\
\hline & & Drain & & & \\
\hline \multirow[t]{4}{*}{ Fatliquoring } & Water & 150 & 55 & & \\
\hline & Lecithin fatliquor & 4 & & & \\
\hline & Sulphonated fatliquor & 2 & & & \\
\hline & $\begin{array}{l}\text { Resistant dielectric } \\
\text { fatliquor }\end{array}$ & 1 & & & \\
\hline Fixing & Formic acid & 2 & & $20 * 3$ & $\mathrm{pH}: 3.5$ \\
\hline
\end{tabular}


Table 3

\begin{tabular}{cccc}
\hline & & Conventional & Experimental \\
\hline $\mathrm{Cr}_{2} \mathrm{O}_{3}$ content in & Wet blue & $3.51 \pm 0.021$ & $3.89 \pm 0.083$ \\
leather $(\%)$ & Resultant leather & $3.99 \pm 0.045$ & $4.33 \pm 0.072$ \\
\hline Shrinkage & Bated hide & $46.3 \pm 0.6$ & $44.9 \pm 0.5$ \\
temperature $\left({ }^{\circ} \mathrm{C}\right)$ & Wet blue & $95.9 \pm 0.5$ & $95.5 \pm 0.3$ \\
\hline
\end{tabular}


Table 4

\begin{tabular}{|c|c|c|c|c|c|c|c|}
\hline & $\begin{array}{c}\mathrm{Cr}_{2} \mathrm{O}_{3}(\mathrm{mg} \bullet \\
\left.\mathrm{L}^{-1}\right)\end{array}$ & $\begin{array}{l}\mathrm{Cl}^{-} \text {content } \\
\left(\mathrm{mmol} \cdot \mathrm{L}^{-1}\right)\end{array}$ & $\begin{array}{c}\mathrm{TDS}(\mathrm{g} \bullet \\
\left.\mathrm{L}^{-1}\right)\end{array}$ & $\begin{array}{l}\mathrm{COD}_{\mathrm{Cr}}( \\
\left.\mathrm{mg} \cdot \mathrm{L}^{-1}\right)\end{array}$ & $\begin{array}{c}\mathrm{BOD}_{5}(\mathrm{~m} \\
\left.\mathrm{g} \cdot \mathrm{L}^{-1}\right)\end{array}$ & $\begin{array}{c}\mathrm{TOC} \\
\left(\mathrm{mg} \cdot \mathrm{L}^{-1}\right)\end{array}$ & $\mathrm{B} / \mathrm{C}$ \\
\hline Conventional & $579.2 \pm 5.2$ & $\begin{array}{c}403.88 \pm 1.2 \\
6\end{array}$ & $\begin{array}{r}604.60 \\
\pm 3.8\end{array}$ & $\begin{array}{c}3,325.2 \pm \\
27.6\end{array}$ & $640 \pm 20$ & $\begin{array}{c}1,194.5 \pm \\
8.7\end{array}$ & 0.19 \\
\hline Experimental & $269.5 \pm 4.1$ & $87.66 \pm 0.98$ & $\begin{array}{r}178.11 \\
\pm 3.2\end{array}$ & $\begin{array}{c}1,856.4 \pm \\
18.3\end{array}$ & $410 \pm 17$ & $\begin{array}{c}770.4 \pm 9 \\
1\end{array}$ & 0.22 \\
\hline
\end{tabular}


Table 5

\begin{tabular}{ccccc}
\hline & $\mathrm{COD}_{\mathrm{Cr}} / \mathrm{mg} \cdot \mathrm{L}^{-1}$ & $\mathrm{BOD}_{5} / \mathrm{mg} \cdot \mathrm{L}^{-1}$ & $\mathrm{TOC} / \mathrm{mg} \bullet \mathrm{L}^{-1}$ & $\mathrm{BOD}_{5} / \mathrm{COD}_{\mathrm{Cr}}$ \\
\hline Conventional & $5,426.4 \pm 35.4$ & $1,716 \pm 12.7$ & $3,508 \pm 25.9$ & 0.31 \\
Experimental & $5,161.2 \pm 36.1$ & $1,592 \pm 11.3$ & $3,128.5 \pm 36.1$ & 0.31 \\
\hline
\end{tabular}


Table 6

\begin{tabular}{cccc}
\hline & $\mathrm{L}$ & $\mathrm{a}$ & $\mathrm{b}$ \\
\hline Conventional & $18.84 \pm 0.32$ & 0.1 & 0.9 \\
Experimental & $18.89 \pm 0.16$ & 0.07 & 0.69 \\
\hline
\end{tabular}




\section{Graphical abstract}

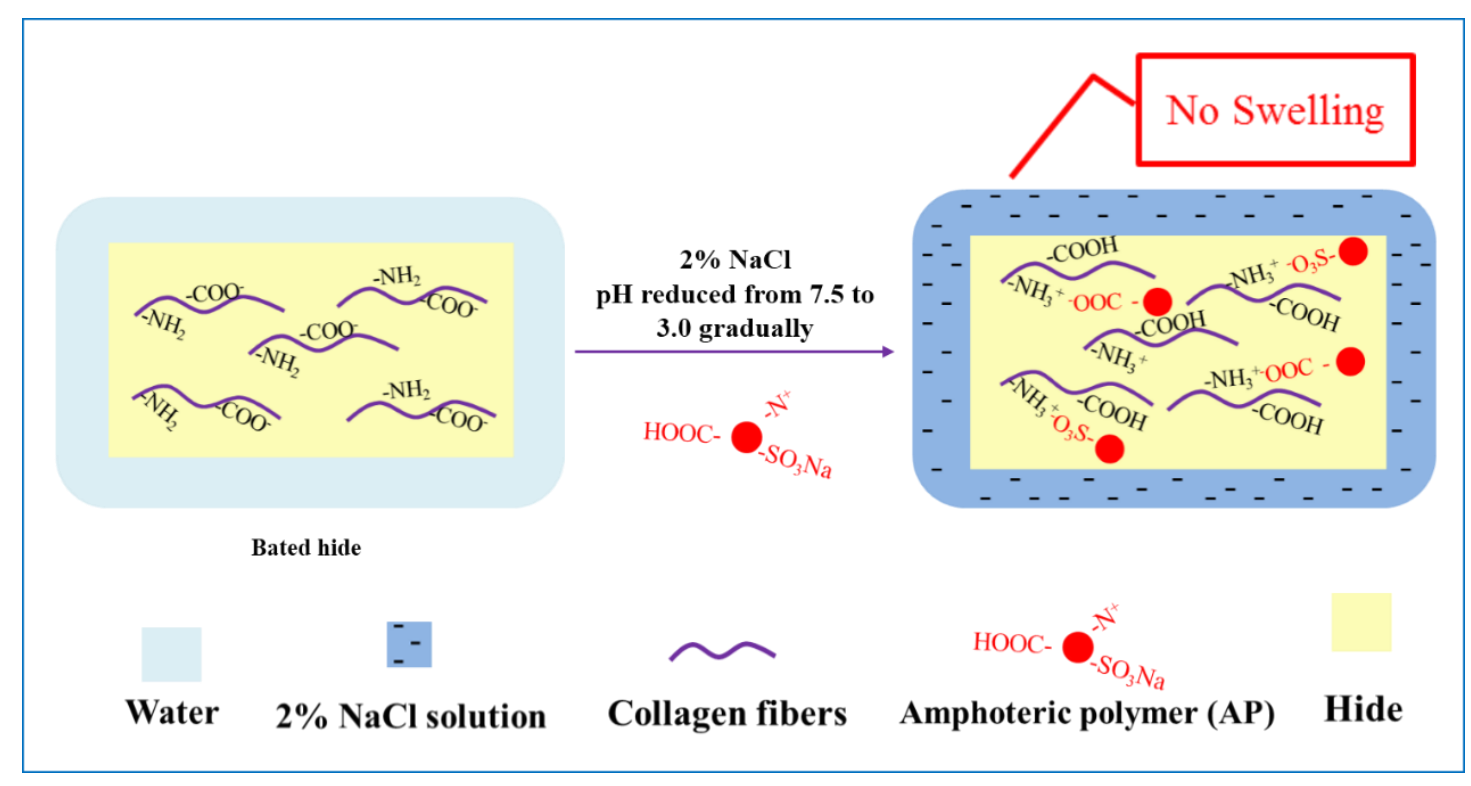

